\title{
Repeatability of lung function tests during methacholine challenge in wheezy infants
}

Christophe Delacourt, Marie-Rose Benoist, Serge Waernessyckle, Patrick Rufin, Jean-Jacques Brouard, Jacques de Blic, Pierre Scheinmann

\begin{abstract}
Background-The repeatability of lung function tests and methacholine inhalation tests was evaluated in recurrently wheezy infants over a one month period using the rapid thoracic compression technique.

Methods-Eighty one wheezy, symptom free infants had pairs of methacholine challenge tests performed one month apart. Maximal flow at functional residual capacity (VंmaxFRC) and transcutaneous oxygen tension $\left(\mathrm{Ptco}_{2}\right)$ were measured at baseline and after methacholine inhalation. Provocative doses of methacholine causing a $15 \%$ fall in $\mathbf{P t c o}_{2}\left(\mathbf{P D}_{15} \mathbf{P t c o}_{2}\right)$ or a $30 \%$ fall in $\dot{V} \operatorname{maxFRC}\left(\mathbf{P D}_{30} \dot{\mathbf{V}}\right.$ maxFRC) were determined.
\end{abstract}

Results-Large changes in $\dot{V}$ maxfrc were measured from $T_{1}$ to $T_{2}$ with a mean difference between measurements $\left(T_{2}-\right.$ $T_{1}$ ) of $7(113) \mathrm{ml} / \mathrm{s}$ and a $95 \%$ range for a single determination for VंmaxFRC of $160 \mathrm{ml} / \mathrm{s}$. The mean (SD) difference between pairs of PD $_{30}$ VmaxfRC measurements was 0.33 (1.89) doubling doses with a $95 \%$ range for a single determination of 2.7 doubling doses. Repeatability of $\mathbf{P D}_{15} \mathbf{P t c o}_{2}$ was similar. A change of 3.7 doubling doses of methacholine measured on successive occasions represents a significant change.

Conclusions-Baseline $\dot{\text { VmaxFRC values }}$ are highly variable in wheezy, symptom free infants. Using either VmaxFRC or $\mathrm{Ptco}_{2}$ as the outcome measure for methacholine challenges provided similar repeatability. A change of more than 3.7 doubling doses of methacholine is required for clinical significance.

(Thorax 1998;53:933-938)

Keywords: bronchiolitis; infantile asthma; bronchial hyperreactivity

Infants often exhibit wheezing with acute lower respiratory illness. The relationship between wheezing symptoms in infancy and asthma remains unclear, and most wheezing infants will stop wheezing after three years of age. ${ }^{1}$ Many authors have tried to relate wheezing illnesses in infants to bronchial hyperresponsiveness by analogy with the association between non-specific bronchial hyperresponsiveness and asthma in older children. However, interpretation of these studies is controversial. In particular, some studies measuring the maximal flow at function residual capacity
(V̇maxFRC) have reported bronchial hyperresponsiveness as being present in all young infants, especially in those younger than one year of age, independent of the presence of wheezing illnesses. ${ }^{2-4}$ If true, these findings would make the detection of bronchial hyperresponsiveness less useful as a marker of infantile asthma. However, assuming that bronchial hyperresponsiveness might be inversely proportional to age during childhood, ${ }^{5}$ it may be possible to characterise asthmatic infants by the persistence of increased bronchial hyperresponsiveness with age. Prospective studies of the natural history of bronchial hyperresponsiveness in wheezing infants are therefore needed. However, the repeatability of both baseline measurements and methacholine inhalation tests in infants over a short period of time needs to be established to allow serial studies of airway hyperreactivity in infants. Such reproducibility over a one month period has been established for children over six years of age ${ }^{6}$ but in infants the reproducibility of lung function tests over time has not been established. Prendiville et $a l^{7}$ reported a high variability in VंmaxFRC and histamine challenge results measured in wheezy infants on two occasions one day apart. On the other hand, Stick et $a l^{8}$ demonstrated a coefficient of repeatability of $31.1 \%$ for VंmaxFRC in healthy infants measured after a one week interval, and an even better repeatability of bronchial challenge. However, the small number of patients tested $(n=10)$ limit the generalisability of the conclusions of the study. The aim of the present study was to evaluate the reproducibility of lung function and methacholine inhalation tests in wheezing infants over a one month period. Two reliable indices were used to detect airway response: VंmaxFRC and transcutaneous oxygen tension $\left(\mathrm{PtcO}_{2}\right)$.

\section{Methods}

SUBJECTS AND STUDY DESIGN

One hundred and two infants (77 boys) of mean (SD) age 14.7 (5.5) months (range 6-26) were recruited from the patients attending the paediatric pneumological unit at Hospital des Enfants Malades in Paris. All had suffered at least three wheezing episodes. Pulmonary function tests were performed twice in each child with a one month interval between the two tests. All infants were asymptomatic for at least two weeks preceding the test. If any respiratory symptoms were observed during this two week period the test was delayed. The response to methacholine inhalation was assessed by both lung function tests and $\mathrm{PtcO}_{2}$.
29 May 1998

Accepted for publication

5 June 1998 


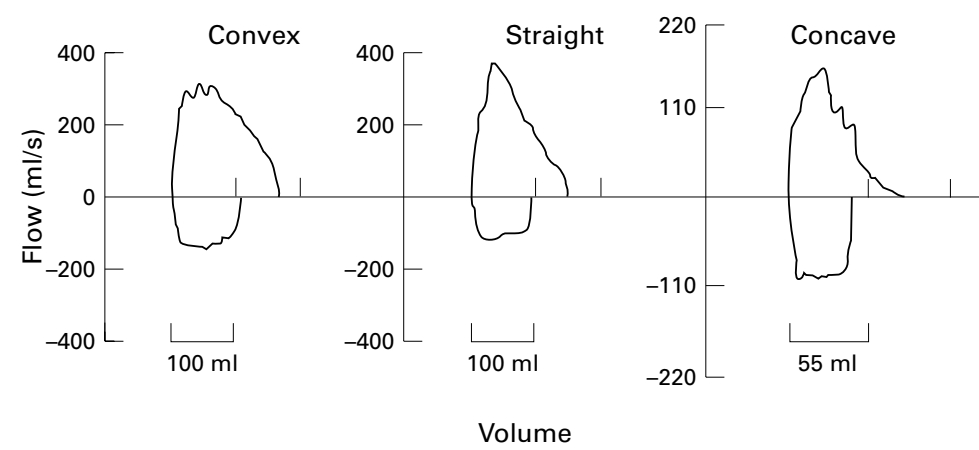

Figure 1 Qualitative description of the shapes of forced expiratory flow-volume curves obtained in wheezy infants: convex, straight and concave curves.

The study was approved by the local ethical committee and informed consent was obtained from all parents.

LUNG FUNCTION TESTS

Infants were sedated with chloral hydrate $(75 \mathrm{mg} / \mathrm{kg}$ ) prior to testing. The maximal partial expiratory flow volume (PEFV) was obtained using the squeeze technique by rapid inflation of a thoracoabdominal jacket at the beginning of expiration (Medical Engineering Department, Royal Postgraduate Medical School, Hammersmith Hospital, London). The jacket was wrapped around the infant's chest and abdomen with the arms extended outside the jacket. The neck was extended to minimise airway or glottic obstruction. All measurements and calculations were obtained using a paediatric mobile Measurement Module (SensorMedics Corporation 2600, Yorba Linda, California, USA) containing the pressure transducers, electronics modules, and 14-bit analogue-to-digital signal converter. Flow was measured at the infant's mouth via a face mask attached to a 0-30 LPM triple screen pneumotachograph with a flow resolution of $0.06 \mathrm{ml} / \mathrm{s}$, a volume resolution of $0.12 \mathrm{ml}$, and a volume range of $0-255 \mathrm{ml}$. A rim of silicone putty was applied around the mouth and nose and to the face mask to provide an airtight seal. Forced expiration was measured as the maximum expiratory flow at functional residual capacity (V́maxFRC) as previously described. ${ }^{9}$ Briefly, partial forced expiratory manoeuvres were performed after at least 10 consecutive regular tidal breaths demonstrated a stable FRC level. This level was defined as the end expiratory level obtained from the respiratory cycle preceding the forced expiratory man-

Table 1 Mean (SD) age, anthropometric data, and lung function test values

\begin{tabular}{|c|c|c|c|}
\hline & \multicolumn{2}{|c|}{ Infants retested $(n=81)$} & $\begin{array}{l}\text { Infants not retested } \\
(n=21)\end{array}$ \\
\hline Age (months) & $15.6(6.8)(7.2-26.0)$ & & $14.2(4.9)(6.1-21.3)$ \\
\hline Height $(\mathrm{cm})$ & $78.6(6.9)(62.3-100.1)$ & & $77.0(5.0)(63.2-98.0)$ \\
\hline Weight (kg) & $10.4(1.8)(6.1-17.3)$ & & $10.1(1.6)(6.2-15.2)$ \\
\hline & First test $\left(\mathrm{T}_{1}\right)$ & Second test $\left(\mathrm{T}_{2}\right)$ & \\
\hline$\dot{\operatorname{VmaxFRC}}(\mathrm{ml} / \mathrm{s})$ & $233(108)$ & $245(110)$ & $221(112)$ \\
\hline CV \% for VंmaxFRC & $8.3(3.2)$ & $8.4(4.9)$ & $9.2(5.1)$ \\
\hline V̇maxFRC (\% pred) & $66.5(29.8)$ & $69.4(31.2)$ & $63.1(32.0)$ \\
\hline $\mathrm{PD}_{15} \mathrm{Ptco}_{2}(\mu \mathrm{g})$ & 233 & 232 & 223 \\
\hline $\mathrm{PD}_{30} \dot{\mathrm{V}} \operatorname{maxFRC}(\mu \mathrm{g})$ & 213 & 294 & 247 \\
\hline
\end{tabular}

Two consecutive tests, one month apart, were performed in 81 of the 102 infants initially included. $\dot{V} \operatorname{maxFRC}=\operatorname{maximal}$ flow at functional residual capacity $; \mathrm{CV}=$ coefficient of variation $; \mathrm{PD}_{15} \mathrm{Ptco}_{2}$ $=$ mean provocative methacholine dose for $\mathrm{Ptco}_{2}$ (geometric mean) $\mathrm{PD}_{30} \dot{\mathrm{V}}$ maxFRC $=$ mean provocative methacholine dose for VंmaxFRC (geometric mean). oeuvre. Because experience with our equipment showed that the jacket pressure necessary to obtain maximal flow was usually between 60 and $80 \mathrm{~cm} \mathrm{H}_{2} \mathrm{O}$, these two pressure levels were used successively. The pressure transmitted from the jacket to the infant was assessed for each infant by an occlusion test and was found to be around $50 \%$ of the jacket pressure. Three PEFV curves were measured for each pressure and a mean baseline value was determined from the highest three of the six technically acceptable values obtained. Criteria for an acceptable PEFV curve included a rapid rise in forced expiratory flow so that the peak flow occurred before expiring $50 \%$ of the tidal volume, a smooth curve without transients in the region of FRC, and forced expiration after FRC.

The shape of the baseline PEFV curves was described qualitatively for each subject as either convex, straight, or concave. ${ }^{10}$ Convex curves (convex away from the expiratory flow and volume axes) are more common in normal infants, and concave or straight curves are more common in those with airway disease. As shown in fig 1, it is straightforward to provide a qualitative description for each curve, as previously shown by Clarke et al. ${ }^{11}$

\section{TRANSCUTANEOUS OXYGEN TENSION}

$\mathrm{PtcO}_{2}$ was measured with a Roche electrode calibrated at room temperature, then heated to $45^{\circ} \mathrm{C}$ and placed on the volar side of the forearm. Transcutaneous oxygen tension was continuously recorded on a chart paper. The baseline value was determined after $\mathrm{PtcO}_{2}$ had reached a stable maximum level. A 15-20 minute period was necessary to obtain a stable value in sleeping infants. After methacholine inhalation the lowest $\mathrm{PtcO}_{2}$ value was taken into account.

\section{METHACHOLINE CHALLENGE}

The aerosol was administered with a dosimeter (MFDC 88, Mediprom, Paris, France) attached to a nebuliser (De Vilbiss $5610 \mathrm{D}$ ), the size of the particles generated by the nebuliser being $1.9 \mu \mathrm{m}$ MMAD. The apparatus was programmed to deliver a dose of $50 \mu \mathrm{g}$ of methacholine in a volume of $40 \mathrm{ml}$ of air in 0.5 seconds. Under these conditions the duration and volume of each aerosol dose could not exceed the inspiratory time and volume of the infants, so each delivered dose was completely inhaled. The dosimeter was triggered by the inspiratory negative buccal pressure via the facial mask applied on the infant's face. The infants initially inhaled normal saline. Two minutes later $\mathrm{PtcO}_{2}$ and lung function were measured. This sequence was repeated after data collection with an initial methacholine dose of $50 \mu \mathrm{g}$ and the methacholine dose was then doubled until $\mathrm{Ptco}_{2}$ decreased by at least $15 \%$ from baseline ${ }^{12}$ or a maximal methacholine dose of $1600 \mu \mathrm{g}$ was inhaled. The change was taken as the maximum deviation from baseline two minutes after each dose, before any lung function tests were performed.

Because the duration of sedation varied between infants and the measurement of lung 


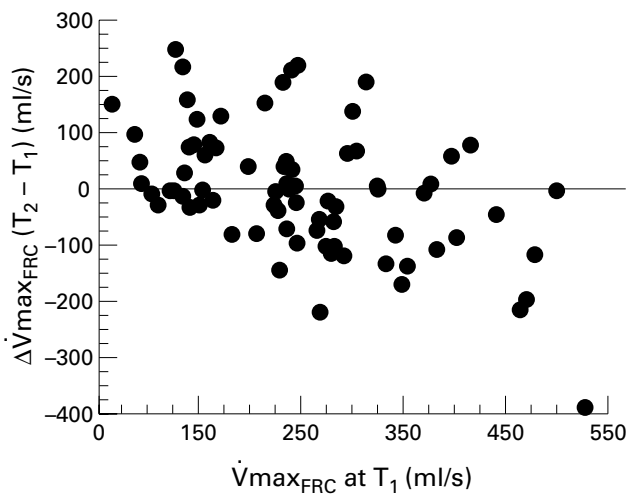

Figure 2 Changes in baseline V maxFRC values from first test $\left(T_{1}\right)$ to second test $\left(T_{2}\right)$. Individual $\dot{V}$ maxFRC values obtained at $T_{1}$ are plotted against their change from $T_{1}$ to $T_{2}(\Delta \dot{V} \max F R C)$, calculated as the absolute value of the difference $\dot{V} \operatorname{maxFRC}$ at $T_{2}$ - $\dot{V} \operatorname{maxFRC}$ at $T_{1}$.

function tests after each dose of methacholine was time consuming, we determined VंmaxFRC only after each dose where $\mathrm{PtcO}_{2}$ changed by more than $5 \%$. A positive response was defined as a fall in mean VंmaxFRC of $30 \%$ or more from baseline.

The provocative dose causing a $15 \%$ fall in $\mathrm{PtcO}_{2}\left(\mathrm{PD}_{15} \mathrm{PtcO}_{2}\right)$ or a $30 \%$ fall in VंmaxFRC ( $\mathrm{PD}_{30} \dot{\mathrm{V}}$ maxFRC) was derived from the plot of log dose methacholine versus $\mathrm{PtcO}_{2}$ or VmaxFRC by linear interpolation between the last two points on the semilogarithmic dose-response graph.

DATA ANALYSIS

All data are expressed as mean (SD). Individual coefficient of variation at baseline was calculated as $\mathrm{SD} /$ mean of the three best measurements (\%).

To compare VंmaxFre values in the wheezy infants with those obtained from normal non-wheezy infants, the data published by Hanrahan $e t \mathrm{al}^{13}$ were used as control VंmaxFRC values. Indeed, Hanrahan and colleagues are the only group to have reported results from a series of normal infants, over eight months of age and the linear relationship observed between length and VmaxFrC (flow at FRC $(\mathrm{ml} / \mathrm{s})=9.67 \times$ body length $(\mathrm{cm})-399.8)$ seems therefore appropriate for use in our study population. Furthermore, the methodology used by Hanrahan and colleagues was consistent with ours and, in particular, they used similar sedation and identical jacket pressure. The VंmaxFRC values obtained in our patients were expressed as absolute values and as a percentage of the control value.

The repeatability of baseline parameters and of the methacholine challenge was assessed using methods recommended by Chinn. ${ }^{14}$ Means of data obtained on the two tests were first compared by a paired $t$ test to ensure that there was no overall bias between the two sets of measurements. The $95 \%$ range for a single determination was best used for measuring repeatability. This is calculated as $\pm 2 \times$ standard deviation of the differences between two tests, divided by the square root of 2 . The $\mathrm{PD}_{15} \mathrm{PtcO}_{2}$ and $\mathrm{PD}_{30} \dot{\mathrm{V}}$ maxFRC data were obtained on a log scale prior to taking differences.
The $95 \%$ range for a single determination was then converted into units of doubling doses by dividing it by $\log _{10}(2)(=0.301)$. As stated by Chinn, ${ }^{14}$ this range may be interpreted as the limits around a single measurement that should be regarded as possible values for the true measurement.

Agreement between evaluation of methacholine challenge by $\mathrm{PD}_{15} \mathrm{PtcO}_{2}$ or $\mathrm{PD}_{30} \mathrm{~V}$ maxFRC was determined on the first test using the methods of Bland and Altman. ${ }^{15} \mathrm{~A}$ paired $t$ test was first performed to compare the means of the two sets of data. The difference between $\mathrm{PD}_{15} \mathrm{Ptc}_{\mathrm{O} 2}$ and $\mathrm{PD}_{30} \dot{\text { VimaxFRC }} \log$ values for each subject were then calculated and plotted against their mean result. The limits of agreement were estimated by $\Delta \pm 2 \mathrm{~s}$, where $\Delta$ was the mean difference between $\mathrm{PD}_{15} \mathrm{PtcO}_{2}$ and $\mathrm{PD}_{30} \dot{\mathrm{V}}$ maxFRC and $\mathrm{s}$ was the standard deviation.

\section{Results}

One hundred and two infants were recruited and underwent a first test $\left(\mathrm{T}_{1}\right)$. A second test $\left(\mathrm{T}_{2}\right)$ was performed in 81 of the 102 infants. Twenty one did not have a second lung function test: four vomited chloral hydrate so the lung function test was precluded, four woke during the measurements, three did not sleep
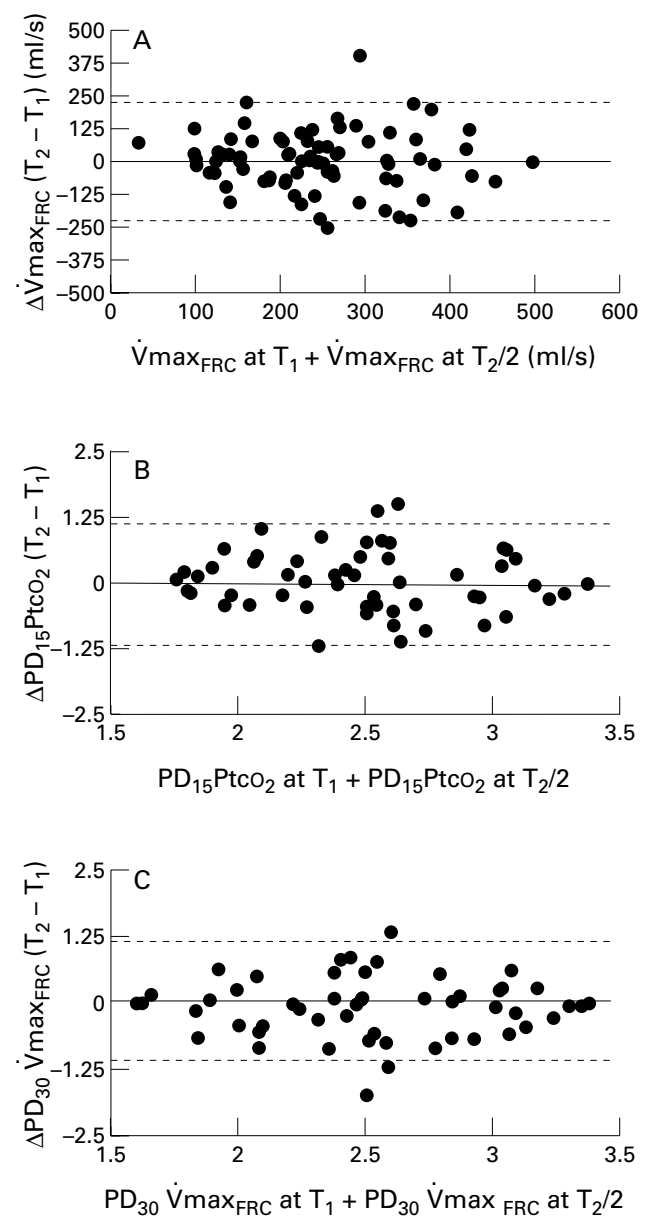

Figure 3 Agreement between measurements obtained at $T_{1}$ and $T_{2}$. The difference between tests is plotted against the average value for the two tests. (A) VMaxFRC in absolute terms (ml/s); (B) $\mathrm{PD}_{15} \mathrm{PtcO}_{2}$ in log terms; (C)

$P D_{30} \dot{V}$ maxFRC in log terms. 


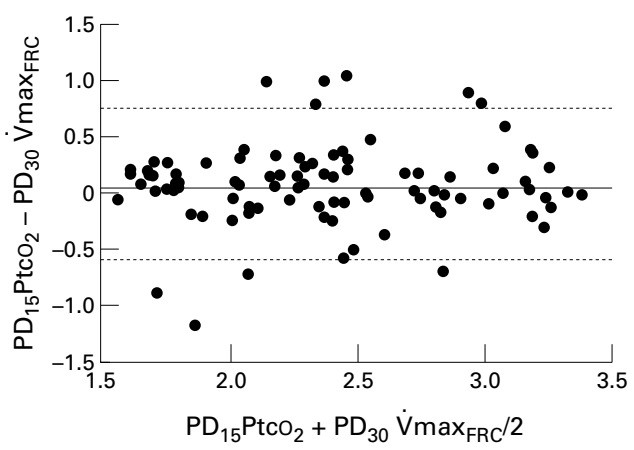

Figure 4 Agreement between $\mathrm{PD}_{15} \mathrm{Ptco}_{2}$ and $P D_{30} \dot{V}$ maxFRC results. Provocative doses are expressed as log dose of methacholine. Agreement was evaluated by plotting the difference between these two variables against their mean.

in spite of $100 \mathrm{mg} / \mathrm{kg}$ chloral hydrate, and in 10 cases the parents refused the second test. There were no significant differences between the 81 who remained in the study and the 21 who withdrew in terms of anthropometric data and baseline VंmaxFRC, as reported table 1. All data are calculated only for the group of infants performing both tests $(n=81)$.

BASELINE LUNG FUNCTION TESTS

Baseline lung function values obtained at $T_{1}$ and $\mathrm{T}_{2}$ are reported in table 1 . When expressed as a percentage of the control values $59 \%$ and $60 \%$ of infants had VंmaxFRC values less than $75 \%$ of the theoretical values at $T_{1}$ and $T_{2}$, respectively. The shape of the PEFV curves was convex in 35 infants and concave or straight in 46 infants. VंmaxFRC values were clearly related to the shape of the PEFV curves; $88 \%$ of infants with VंmaxFRC values below $75 \%$ of theoretical values had straight or concave PEFV curves whereas $90 \%$ of infants with $\dot{V}$ maxFRC values greater than or equal to $75 \%$ had convex PEFV curves. The individual coefficient of variation $(\mathrm{CV})$ at baseline calculated for the three best $\dot{V}$ maxFRC measurements at $\mathrm{T}_{1}$ was 8.3 (3.2)\% (range 2.2-13.1). No significant difference was observed at $\mathrm{T}_{2}$ with $\mathrm{CV}$ ranging from 2.3 to 16.1 (table 1 ).

No significant difference was observed for baseline VंmaxFRC between $\mathrm{T}_{1}$ and $\mathrm{T}_{2}(\mathrm{p}=$ 0.877 ; paired $t$ test). Baseline $\dot{V}$ maxFrC increased from $T_{1}$ to $T_{2}$ in $46 \%$ of infants and decreased in $46 \%$ of infants (fig 2); it remained stable in $8 \%$ of children. The mean (SD) difference between measurements $\left(\mathrm{T}_{2}-\mathrm{T}_{1}\right)$ was 7 (113) $\mathrm{ml} / \mathrm{s}$ (fig 3A). Thus, the $95 \%$ range for a single determination for $\dot{V}$ maxFRC was $160 \mathrm{ml} / \mathrm{s}$. Large improvements in VंmaxFRC from $T_{1}$ to $T_{2}$ were observed in infants with initially low $\dot{V}$ maxFRC values $(<75 \%$ theoretical values at $\mathrm{T}_{1}$ ) with a mean difference of 34 (94) $\mathrm{ml} / \mathrm{s}(\mathrm{n}=50)$ and a $95 \%$ range for a single determination of $133 \mathrm{ml} / \mathrm{s}$. On the other hand, significant deterioration was seen in infants with VmaxFRC values $\geqslant 75 \%$ of the theoretical value at $\mathrm{T}_{1}(\mathrm{n}=31)$ with a mean difference of $-52(122) \mathrm{ml} / \mathrm{s}$ and a $95 \%$ range for a single determination of $172 \mathrm{ml} / \mathrm{s}$.
METHACHOLINE INHALATION CHALLENGES Agreement between $\mathrm{PD}_{15} \mathrm{PtcO}_{2}$ AND $\mathrm{PD}_{30} \dot{V}_{M A X F R C}$ results

Response to methacholine challenge was evaluated by both $\mathrm{PD}_{15} \mathrm{PtcO}_{2}$ and $\mathrm{PD}_{30} \dot{\mathrm{V}}$ maxFrC and mean results are reported in table 1 . At $T_{1}$ and $\mathrm{T}_{2}$ there were 13 and 12 infants, respectively, who were non-responders $(>1600 \mu \mathrm{g})$. Agreement between $\mathrm{PD}_{15} \mathrm{PtcO}_{2}$ and $\mathrm{PD}_{30}$ VmaxFRC was evaluated by plotting the difference between these two variables measured at $T_{1}$ against their mean (fig 4). The mean (SD) difference between $\mathrm{PD}_{30} \dot{V}$ maxFRC and $\mathrm{PD}_{15} \mathrm{PtcO}_{2}$ was -0.281 (1.16) doubling doses, giving limits of agreement for $\mathrm{PD}_{30} \dot{\mathrm{V}}$ maxFRC in relation to $\mathrm{PD}_{15} \mathrm{PtcO}_{2}$ of -2.601 to 2.039 doubling doses.

$\mathrm{PD}_{15} \mathrm{PtcO}_{2}$ and $\mathrm{PD}_{30} \dot{\mathrm{V}} \operatorname{maxFRC}$ values were correlated with baseline $\dot{V} \operatorname{maxFRC}$ values and lower results were obtained in infants with lower lung function $(r=0.285 ; \mathrm{p}<0.002$ and $r$ $=0.401 ; \mathrm{p}<0.0001$, respectively)

\section{Methacholine repeatability}

Eighty one infants had two methacholine challenges one month apart. From the 13 nonresponders at $T_{1}$, six were responders at $T_{2}$ and five responders at $T_{1}$ were non-responders at $\mathrm{T}_{2}$. No significant difference was observed between $T_{1}$ and $T_{2}$ for $\mathrm{PD}_{15} \mathrm{PtcO}_{2}(\mathrm{p}=0.944$; paired $t$ test) or $\mathrm{PD}_{30} \dot{\mathrm{V}} \operatorname{maxFRC}(\mathrm{p}=0.586$; paired $t$ test). The mean (SD) difference between the $\mathrm{PD}_{15} \mathrm{PtcO}_{2}$ results obtained for each challenge was -0.13 (1.87) doubling doses (fig 3B). The $95 \%$ range for a single determination was therefore 2.6 doubling doses for a single determination. The use of $\mathrm{PD}_{30} \dot{\mathrm{V}}$ maxFRC gave similar repeatability results, the mean (SD) difference between the results obtained for each challenge being 0.33 (1.89) doubling doses (fig 3C), giving a 95\% range for a single determination of 2.7 doubling doses.

\section{Discussion}

The repeatability of lung function tests during methacholine challenge was evaluated in recurrently wheezy infants over a one month period. Our results showed a high variability in baseline VंmaxfRC values and both VmaxFRC and $\mathrm{PtcO}_{2}$ showed similar repeatability as parameters for methacholine challenges. Because of the variability in the changes in these parameters, only large concentration changes measured on successive occasions may be considered clinically significant in wheezy infants.

\section{BASELINE LUNG FUNCTION TESTS}

A large range of $\dot{V}$ maxFRC values were obtained in our wheezy infants. Despite the fact that all the infants were clinically asymptomatic when tested, $60 \%$ had VmaxFRC values below $75 \%$ of the expected value for their body length. Baseline VmaxFRC values have been reported to be lower in recurrently wheezy but symptom free infants than in healthy infants. ${ }^{391617}$ It has therefore been proposed that the main predisposing factor for recurrent wheeze in infancy is abnormally small airways. ${ }^{16}$ Reduced airway function has also been reported to precede wheezing illness. ${ }^{18}$ However, although the 
mean $\dot{V}$ maxFRC values in our population were lower than the expected mean, a relationship between this observation and congenitally small airways is not supported by our data. Indeed, a large proportion $(40 \%)$ of our subjects had normal VmaxFRC values and these infants were easily identified by the convex shape of their flow-volume curve. This subgroup of wheezy infants did not differ significantly from normal infants reported by Hanrahan et al. ${ }^{13}$ Thus, the low mean VmaxFRC value in our study population was due to wheezy, symptom free infants with straight or concave flow-volume curves. Small airways in these infants may be expected to result in repeatedly low VंmaxfRC values when tests were performed on different days. On the other hand, we found a very high variability in VंmaxFRC with a $95 \%$ range for a single determination of $160 \mathrm{ml} / \mathrm{s}$. Theoretically, technical factors may contribute to the variability in VMaxFRC. Indeed, the measurement of VmaxFRC relies on FRC which is usually dynamically determined in young infants. In particular, FRC shifts with many dynamic events including changes in airway calibre and sleep state..$^{19}$ Any modification in airway calibre during methacholine challenge may induce changes in FRC which might influence measurements obtained from partial expiratory flow-volume curves but are not evaluable in routine use. Coefficients of variation for VMaxFRC during one test were found to be relatively high, ranging from $8 \%$ to $16 \%$. However, these values are too low for technical factors to be the sole explanation for the very high variability found between the two tests for VmaxFRC in our study. Large changes in $\dot{V}$ maxFRC from $T_{1}$ to $T_{2}$ were observed in both directions-improvement and deterioration-arguing for a great lability of airway calibre in infants independent of clinical symptoms rather than for fixed small airways. Such large changes in VंmaxFRC with time have previously been reported for healthy infants with a $31 \%$ coefficient of variability. ${ }^{8}$ If changes in VmaxFRC in our study were expressed as a percentage of the change from $T_{1}$, the mean change in the subgroup of wheezy infants with initially normal VmaxFRC values was -14 (34) $\%$ with a $95 \%$ range for a single determination of $48 \%$ of baseline, very similar to the value previously reported in healthy infants. ${ }^{8}$

METHACHOLINE CHALLENGE: FIRST ANALYSIS OF REPEATABILITY IN A LARGE POPULATION OF WHEEZY INFANTS

In this study we have tried to establish the repeatability of methacholine inhalation tests in wheezy infants. Knowledge of the repeatability is required for the study of the natural history of airway hyperreactivity in wheezy infants. This question has previously been addressed only by Prendiville et $a l^{7}$ who gave 10 wheezy infants two challenges at an interval of 1-5 days. The reproducibility was poor with a $95 \%$ confidence interval of 4.5 doubling concentrations. With a much larger group of wheezy infants we obtained better repeatability results for methacholine challenges than that previously reported, with a $95 \%$ range for a single determination of 2.6 doubling doses. Similar results have also been reported for adults. Trigg et al studied the daily variability in bronchial responsiveness to methacholine in adult asthmatic patients and found a 95\% range for repeatability of \pm 2.36 doubling doses. ${ }^{20}$ However, most studies performed in adults and children older than six years of age showed better repeatability results than those we obtained in wheezy infants. In particular, Phagoo et al performed two methacholine challenges with a one day interval in children aged 6-12 years and reported coefficients of repeatability of \pm 0.96 and \pm 0.80 doubling doses for $\mathrm{PD}_{15} \mathrm{PtcO}_{2}$ and $\mathrm{PD}_{20} \mathrm{FEV}_{1}$, respectively. ${ }^{21}$ Furthermore, Stick et al reported a coefficient of repeatability of 1.66 doubling concentrations in healthy infants challenged twice with histamine with a one week interval. ${ }^{8}$ Many factors may contribute to the increased variability of methacholine challenges in our population. Firstly, $\mathrm{PD}_{15} \mathrm{PtcO}_{2}$, or $\mathrm{PD}_{30}$ VंmaxFRC are influenced by baseline bronchial obstruction. This phenomenon has previously been reported $^{7}$ and is confirmed in the present study. We found a high variability in baseline VंmaxFRC values and this may contribute substantially to the increase in the coefficient of repeatability for methacholine inhalation challenge. Secondly, technical factors may also influence repeatability. In particular, variability in methacholine aerosol deposition pattern, depending on tidal volume, degree of sleep and inspiratory airflow, may contribute to changes in methacholine provocative doses. Tal et al reported a large difference in the deposition of radiolabelled drug in wheezy infants and adults, the mean aerosol deposition in the lungs being only $2 \%$ in infants and $19 \%$ in adults. ${ }^{22}$

Knowledge of the repeatability of methacholine inhalation tests is particularly important when these tests are to be repeated in the same children to monitor the natural history of respiratory diseases or therapeutic interventions. A clinically significant change for an individual patient can be derived from a single determination of the $95 \%$ range provided the square root of 2 is included. ${ }^{14}$ Thus, from our data, a change in $\mathrm{PD}_{15} \mathrm{PtcO}_{2}$ of more than 3.7 doubling doses measured on successive occasions may be considered clinically significant in wheezy infants.

Methacholine induced bronchial hyperreactivity was assessed by measuring both $\mathrm{PD}_{15} \mathrm{PtcO}_{2}$ and $\mathrm{PD}_{30}$ Vmaxfrc. $\mathrm{PD}_{15} \mathrm{PtcO}_{2}$ is now widely used as a sensitive index for detecting bronchial responsiveness during methacholine challenge, ${ }^{212324}$ even in infants. ${ }^{91125}$ $\mathrm{PD}_{30} \dot{\mathrm{V}}$ maxFRC was found to be as sensitive as $\mathrm{PD}_{15} \mathrm{PtcO}_{2}$ and in agreement with $\mathrm{PD}_{15} \mathrm{PtcO}_{2}$ within a twofold concentration difference. Although this difference remains lower than the coefficient of repeatability of both $\mathrm{PD}_{15} \mathrm{Ptco}_{2}$ and $\mathrm{PD}_{30} \dot{\mathrm{V}}$ maxFRC, the relatively wide limits of agreement do not allow these two variables to be used interchangeably. Furthermore, advantages and limitations for these two methods are different. $\mathrm{PtcO}_{2}$ reflects changes in pulmonary blood flow and ventilationperfusion mismatch and is not measuring the 
same thing as $\dot{V}$ maxFRC, which is probably a closer reflection of lung mechanics. VंmaxFRC allows a baseline evaluation of bronchial obstruction, which is not possible with $\mathrm{PtcO}_{2}$. However, $\mathrm{PtcO}_{2}$ has the advantage of being easily measured, even for infants who are awake, and thus allows repeated testing without repeated sedation.

In conclusion, our study show that baseline $\dot{V} \operatorname{maxFRC}$ values are highly variable in wheezy, symptom free infants. The use of either VmaxFRC or $\mathrm{PtcO}_{2}$ as a parameter for methacholine challenge gave similar repeatability results in wheezy infants. A change of 3.7 doubling doses of methacholine measured on successive occasions is required for clinical significance.

1 Martinez FD, Wright AL, Taussig LM, et al and the group health medical associates. Asthma and wheezing in the first
six years of life. $N$ Engl F Med 1995;332:133-8.

2 Le Souëf PN, Geelhoed GC, Turner DJ, et al. Response of normal infants to inhaled histamine. Am Rev Respir Dis 1989;139:62-6.

3 Clarke JR, Reese A, Silverman M. Bronchial responsiveness and lung function in infants with lower respiratory tract illness over the first six months of life. Arch Dis Child 1992;67:1454-8.

4 Tepper RS. Airway reactivity in infants: a positive response to methacholine and metaproterenol. $f$ Appl Physiol 1987;62:1155-9.

5 Montgomery GL, Tepper RS. Changes in airway reactivity with age in normal infants and young children. Am Rev Respir Dis 1990;142:1372-6.

6 Weiss ME, Wheeler B, Eggleston P, et al. A protocol for performing reproducible methacholine inhalation tests in chil forming reproducible methacholine inhalation tests in chil1989;139:67-72.

7 Prendiville A, Green S, Silverman M. Bronchial responsiveness to histamine in wheezy infants. Thorax 1987;42:92-9.

8 Stick SM, Turner DJ, Lesouëf PN. Lung function and bronchial challenges in infants: repeatability of histamine and comparison with methacholine challenges. Pediatr Pulmonol 1993;16:177-83.

9 Benoist MR, Brouard JJ, Rufin P, et al. Ability of new lung function tests to assess methacholine-induced airway obstruction in infants. Pediatr Pulmonol 1994;18:308-16.
10 Le Souëf PN, Hughes DM, Landau LI. Effect of compression pressure on forced expiratory flow in infants. $f$ Appl Physiol 1986;61:1639-46.

11 Clarke JR, Reese A, Silverman M. Comparison of the squeeze technique and transcutaneous oxygen tension for measuring the response to bronchial challenge in normal and wheezy infants. Pediatr Pulmonol 1993;15:244-50.

12 Van Broekhoven P, Hop WCJ, Rasser E, et al. Comparison of $\mathrm{FEV}_{1}$ and transcutaneous oxygen tension in the of $\mathrm{FEV}_{1}$ and transcutaneous oxygen tension in the measurement of airway responsiveness to me
and dilatation. Pediatr Pulmonol 1991;11:254-8.

13 Hanrahan JP, Tager IB, Castile RG, et al. Pulmonary function measures in healthy infants. Variability and size correction. Am Rev Respir Dis 1990;141:1127-35.

14 Chinn S. Statistics in respiratory medicine. 2. Repeatability and method comparison. Thorax 1991;46:454-6.

15 Bland JM, Altman DG. Statistical methods for assessing agreement between two methods of clinical measurement. Lancet 1986;i:307-10.

16 Stick SM, Arnott J, Turner DJ, et al. Bronchial responsiveness and lung function in recurrently wheezy infants. $\mathrm{Am}$ Rev Respir Dis 1991;144:1012-5.

17 Tepper RS, Rosenberg D, Eigen H. Airway responsiveness in infants following bronchiolitis. Pediatr Pulmonol 1992;13: $6-10$.

18 Martinez FD, Morgan WJ, Wright AL, et al. Initial airway function is a risk factor for recurrent wheezing respiratory illnesses during the first three years of life. Am Rev Respir Dis 1991;143:312-6.

19 Stocks J, Sly PD, Tepper RS, et al. Infant respiratory function testing. New York: John Wiley, 1996: 381.

20 Trigg CJ, Jhalli N, Herdman MJ, et al. The daily variability of bronchial responsiveness to methacholine. Eur Respir $\mathcal{F}$ 1990;3:867-71.

21 Phagoo SB, Wilson NM, Silverman M. Repeatibility of methacholine challenge in asthmatic children measured by change in transcutaneous oxygen tension. Thorax 1992;47: 804-8.

22 Tal A, Golan H, Grauer N, et al. Deposition pattern of radiolabeled salbutamol inhaled from a metered-dose inhaler by means of a spacer with mask in young children with airway obstruction. F Pediatr 1996;128:479-84.

23 Bisgaard $\mathrm{H}$, Klug B. Lung function measurement in awake young children. Eur Respir f 1995;8:2067-75.

24 Wilts M, Hop WCI, van der Heyden GHC, et al. Measurement of bronchial responsiveness in young children: comparison of transcutaneous oxygen tension and funccomparison of transcutaneous oxygen tension and func-
tional residual capacity during induced bronchoconstriction and -dilatation. Pediatr Pulmonol 1992;12:181-5.

25 Prendiville A, Maxwell DL, Rose A, et al. Histamineinduced airway obstruction in infancy: changes in oxygenation. Pediatr Pulmonol 1988;4:164-8. 